|IIIIIIIIIIIIIIIIIIIIIIIIIIIIIIIIII

Technical Report

IIIIIIIIIIIIIIIIIIIIIIIIIIIIIIIIIIIII

\title{
Highly sensitive analytical method for herbicide clopyralid residue in cattle manure compost with ultraperformance liquid chromatography tandem mass spectrometry
}

\author{
Eiki Watanabe,* Nobuyasu Seike and Sayuri Namiki \\ Division of Hazardous Chemicals, Institute for Agro-Environmental Sciences, National Agriculture and Food Research Organization (NARO), \\ 3-1-3 Kannondai, Tsukuba, Ibaraki 305-8604, Japan
}

(Received March 19, 2019; Accepted March 23, 2019)

\begin{abstract}
A micro liquid-liquid extraction has been applied to sample preparation in the current authorized method for clopyralid in compost. The method rendered matrix effects practically negligible during determination with ultraperformance liquid chromatography-electrospray ionization tandem mass spectrometry with an improved limit of quantification of $0.7 \mu \mathrm{g} / \mathrm{kg}$ dry weight. Moreover, it had good accuracy and reproducibility. Therefore, the method is proposed as a highly effective routine analytical technique for investigating the actual status of clopyralid residue in compost. () Pesticide Science Society of Japan

Keywords: analytical validation, clopyralid, compost, LC-MS/MS, micro liquid-liquid extraction, sample preparation.

Electronic supplementary materials: The online version of this article contains supplementary materials (Supplemental Fig. S1), which is available at http://www.jstage.jst.go.jp/browse/jpestics/
\end{abstract}

\section{Introduction}

Clopyralid (3,6-dichloropyridine-2-carboxylic acid) is known as a selective and systemic herbicide showing an auxin-like action. This herbicide, which is mainly used to control various annual and perennial broadleaf weeds in areas with cultivated crops such as sugar beets, fodder beets, and maize, is also used for weeding in pastures and non-crop land. ${ }^{1)}$ Physiological disorders of horticultural crops such as vegetables and flowers suspected to result from clopyralid in cattle manure compost have been confirmed in Japan. ${ }^{2}$ The following are regarded as factors contributing to physiological disorders caused by clopyralid: (1) Degradation is slow, depending on the soil type; thus clopyralid persists for long periods in the soil. (2) Clopyralid remains to a greater or lesser degree in crops, including forage cultivated in soil with herbicide residue. (3) Most clopyralid is excreted promptly in manure without being metabolized in livestock that have consumed feed crops with clopyralid residue. ${ }^{1)}$ (4) By application to soil of clopyralid-contaminated compost that includes excrement as a raw material, damage to horticultural crop production has been particularly great. Namiki et al. ${ }^{3)}$ report that physiological disorders might arise, depending on highly susceptible crops, even at low clopyralid concentrations in soil of

\footnotetext{
* To whom correspondence should be addressed.

E-mail: eikiw@affrc.go.jp

Published online May 30, 2019

(c) Pesticide Science Society of Japan
}

around $1 \mu \mathrm{g} / \mathrm{kg}$, although the degree to which the physiological disorder appears depends on the crop. ${ }^{4)}$

Given this background, Japan, which is approximately $75 \%$ dependent on imported feed, is conducting a survey of clopyralid residue concentrations in imported feed and compost produced from livestock excrement. ${ }^{5,6)}$ In Japan, the authorized Testing Methods for Fertilizers $(2017)^{7)}$ have been used for monitoring surveys as an analytical method for clopyralid residue in compost. However, the detection of remaining clopyralid in the low concentration range described above is impossible as a practical matter because the limit of quantification (LOQ) of the analytical method is about $10 \mu \mathrm{g} / \mathrm{kg}$. Therefore, the establishment of an analytical method with 10 times higher LOQ sensitivity than the current method is urgently needed.

Analysis of clopyralid using high-performance liquid chromatography (HPLC) is the mainstream method. ${ }^{8-15)}$ For analytical methods of clopyralid using gas chromatography (GC), derivatization before determination is necessary. ${ }^{16-19)}$ Therefore, the analytical operation is generally complicated. Today, liquid chromatography or ultraperformance liquid chromatography equipped with tandem mass spectrometry (LC-MS/MS ${ }^{8,9,11,13)}$ or UPLC-MS/MS ${ }^{10,12,14,15)}$ ) is the prominent method for analyzing pesticide residues in various matrices. It is being applied routinely to analyze clopyralid, as described above. When establishing a residual analytical method for clopyralid, investigating the sample-preparation method (extraction method and cleanup method of crude sample extracts) appropriately before chromatographic determination is important to achieve out- 
standing analytical performance of LC-MS/MS. The most problematic issue in determination with LC-MS/MS is the influence on ionization caused by matrix components coexisting with target pesticides derived from a sample, i.e., matrix effect. ${ }^{20-23)}$ To reduce the matrix effect, it is necessary to clean up the sample extracts thoroughly. ${ }^{21)}$ However, as the complexity of the sample-preparation procedure increases, the possibility of losing the target pesticides during the procedure might also increase. A means is adopted to correct the matrix effect using an external or internal matrix-matched calibration method. ${ }^{20-23)}$ Because clopyralid shows changes in the physicochemical properties as a result of its $\mathrm{pH}$ dependence $\left(\mathrm{p} K_{\mathrm{a}}=2.0\right)$ and high water solubility $\left(7,850 \mathrm{mg} / \mathrm{L}\right.$ (in distilled water), $\log K_{\mathrm{ow}}=-2.63$ (at pH 7)), ${ }^{1)}$ establishing a residual analytical method for complicated matrices such as compost will probably be difficult. Clopyralid is therefore regarded as a problematic pesticide. ${ }^{13)}$

This study examined a sample-preparation method with a new concentration process based on extraction using methanol under alkaline and a cleanup method using solid-phase extraction (SPE) cartridges pre-packed with a copolymer of $\mathrm{N}$-vinylpyrrolidone (hydrophilic) and divinylbenzene (lipophilic) adopted in the Testing Methods for Fertilizers (2017). ${ }^{7)}$ The method is expected to increase the analytical sensitivity of a residual analytical method for clopyralid in compost, a complicated matrix.

\section{Materials and Methods}

\section{Chemicals and materials}

Pesticide residue analysis-grade clopyralid with purity of $99.3 \%$ (by HPLC) was purchased from Wako Pure Chemical Industries Ltd. (Osaka, Japan). All other chemicals were of LC-MS grade, HPLC grade, pesticide residue analysis grade, or analytical grade. Water used to prepare a mobile phase for UPLC-MS/MS was prepared directly in the laboratory using a Milli-Q water purification system (Millipore Corp., Bedford, MA, USA).

The stock solution $(1 \mathrm{mg} / \mathrm{mL})$ of clopyralid was prepared by dissolving $10 \mathrm{mg}$ of the standard in $10 \mathrm{~mL}$ of HPLC-grade acetonitrile. It was stored in the dark at $4^{\circ} \mathrm{C}$. A working standard solution $(20 \mu \mathrm{g} / \mathrm{mL})$ was prepared daily, diluting the primary stock solution with $0.1 \%$ formic acid to obtain calibration standards with concentrations of $1-100 \mathrm{ng} / \mathrm{mL}$. These standard solutions were used to prepare UPLC-MS/MS calibration curves.

\section{Sample}

Air-dried, commercially available cattle manure compost samples were crushed with a variable-speed rotor mill (Pulverisette 14; Fritsch $\mathrm{GmbH}$, Idar-Oberstein, Germany) equipped with a sieve ring $(500 \mu \mathrm{m})$.

\section{Sample-preparation procedure}

\subsection{Proposed method}

\subsubsection{Extraction}

Five grams of a spiked or clopyralid-contaminated sample was weighed into a $100 \mathrm{~mL}$ Erlenmeyer flask with a screw cap. After methanol-1 $\mathrm{MNaOH}(99: 1)(50 \mathrm{~mL})$ was added to the sample, the sample mixture was shaken vigorously for $30 \mathrm{~min}$ using a reciprocating shaker. The sample mixture was transpired to a $50 \mathrm{~mL}$ glass centrifuge tube. Then it was centrifuged for $5 \mathrm{~min}$ at $1,700 \times g$ using a low-speed centrifuge. The solid residue was shaken again with $40 \mathrm{~mL}$ of methanol-1 $\mathrm{MNaOH}(99: 1)$. The two sample extracts were filtered through a glass fiber filter under suction and were then made up to $100 \mathrm{~mL}$ with methanol-1 M NaOH $(99: 1)$.

\subsubsection{Cleanup with solid-phase extraction (SPE) cartridge}

A $10 \mathrm{~mL}$ aliquot of the sample extract (equivalent to $0.5 \mathrm{~g}$ of the sample) was loaded into an SPE cartridge that had been prepacked with a hydrophilic-lipophilic balanced sorbent $(225 \mathrm{mg}$, Oasis HLB; Waters Corp., Milford, MA, USA) preconditioned with $5 \mathrm{~mL}$ of methanol and $5 \mathrm{~mL}$ of Milli-Q water. The retained clopyralid was eluted with $10 \mathrm{~mL}$ of methanol-0.01 $\mathrm{M} \mathrm{NaOH}$ $(1: 1)$. Methanol $(5 \mathrm{~mL})$ was added to the eluate. Then the solution was concentrated to about $5 \mathrm{~mL}$ under reduced pressure at a water bath temperature of $40^{\circ} \mathrm{C}$. To the concentrated solution, $3 \mathrm{~mL}$ of $1 \mathrm{MHCl}$ was added. Then the solution was loaded into another new Oasis HLB SPE cartridge that had been preconditioned with $5 \mathrm{~mL}$ of acetonitrile and $5 \mathrm{~mL}$ of $0.1 \mathrm{MHCl}$. The cartridge was washed with $10 \mathrm{~mL}$ of $0.1 \mathrm{M} \mathrm{HCl}, 5 \mathrm{~mL}$ of acetonitrile- $0.1 \mathrm{MHCl}(1: 9)$, and $5 \mathrm{~mL}$ of water. The retained clopyralid was eluted into a $10 \mathrm{~mL}$ glass conical centrifuge tube with a screw cap, along with $4 \mathrm{~mL}$ of acetonitrile- $0.0028 \% \mathrm{NH}_{3}$ solution $(1: 9)$.

\subsubsection{Micro liquid-liquid extraction (micro LLE)}

The $\mathrm{pH}$ of the eluate was adjusted to approximately 14 by adding $100 \mu \mathrm{L}$ of $1 \mathrm{MNaOH}$. After $2 \mathrm{~mL}$ of dichloromethane was added to the solution, the mixture was vortexed for $0.5 \mathrm{~min}$ and was centrifuged for $3 \mathrm{~min}$ at $1,700 \times g$. The organic phase was extracted carefully using a microsyringe (Hamilton Co., Reno, $\mathrm{NV}$, USA) and discarded. This washing step was repeated twice. To the aqueous phase, $150 \mu \mathrm{L}$ of $12 \mathrm{M} \mathrm{H}_{2} \mathrm{SO}_{4}$ was added; then the $\mathrm{pH}$ was adjusted to approximately 1 . After $2 \mathrm{~mL}$ of dichloromethane was added to the acidified solution, the mixture was vortexed for $0.5 \mathrm{~min}$ and was centrifuged for $3 \mathrm{~min}$ at $1,700 \times \mathrm{g}$. The organic phase was collected carefully using a microsyringe. This extraction step was repeated three times. After the organic phase was concentrated under reduced pressure, it was evaporated to dryness using a gentle stream of nitrogen at $40^{\circ} \mathrm{C}$. The residue was reconstituted in $200 \mu \mathrm{L}$ of $0.1 \%$ formic acid. The final solution was filtered for $5 \mathrm{~min}$ at $8,000 \times \mathrm{g}$ using a centrifugal filter $(0.22 \mu \mathrm{m}$ PVDF filter; Merck Millipore Ltd., Tullagreen Carrigtwohill, Cork, Ireland) (matrix equivalent to $2.5 \mathrm{~g}$ of sam$\mathrm{ple} / \mathrm{mL})$.

\subsection{Reference method}

The authorized method for analysis of clopyralid residue in compost samples listed in the Testing Methods for Fertilizers $(2017)^{7)}$ was used as a reference method to verify the performance of the proposed method.

\subsubsection{Extraction}

Five grams of compost sample was weighed into a $200 \mathrm{~mL}$ Erlen- 
Table 1. Validity of the number of extraction repetitions using clopyralid-contaminated cattle manure compost samples

\begin{tabular}{|c|c|c|c|c|}
\hline \multirow{2}{*}{ Sample No. } & \multicolumn{2}{|c|}{ Extraction by repeated extraction ( 2 times) (proposed method) } & \multicolumn{2}{|c|}{ Extraction by single extraction (reference method) } \\
\hline & Detected concentration $(\mu \mathrm{g} / \mathrm{kg} \mathrm{dw}, n=5)$ & RSD (\%) & Detected concentration $(\mu \mathrm{g} / \mathrm{kg} \mathrm{dw}, n=5)$ & RSD (\%) \\
\hline 1 & $21.2 \pm 0.4$ & 2.0 & $18.5 \pm 0.3$ & 1.6 \\
\hline 2 & $93.0 \pm 4.2$ & 4.5 & $73.2 \pm 3.1$ & 4.2 \\
\hline 3 & $228.9 \pm 0.4$ & 0.2 & $177.0 \pm 5.0$ & 2.8 \\
\hline
\end{tabular}

meyer flask with a screw cap. After methanol-1 $\mathrm{MNaOH}(99: 1)$ $(100 \mathrm{~mL})$ was added to the sample, the sample mixture was shaken vigorously for $30 \mathrm{~min}$ with a reciprocating shaker. After standing, the supernatant was centrifuged for $5 \mathrm{~min}$ at $1,700 \times g$.

\subsubsection{Cleanup}

A $5 \mathrm{~mL}$ aliquot of the sample extract (equivalent to $0.25 \mathrm{~g}$ of the sample) was cleaned up according to the method described in Section 3.1.2. The volume of the eluate from the second cartridge was accurately adjusted to $5 \mathrm{~mL}$ with $0.1 \%$ formic acid. Then the solution was centrifuged for $5 \mathrm{~min}$ at $8,000 \times \mathrm{g}$. The supernatant was analyzed as a final solution (matrix equivalent to $0.05 \mathrm{~g}$ of the sample $/ \mathrm{mL}$ ).

\section{Analytical condition of UPLC-MS/MS}

LC-MS/MS analyses were conducted using a UPLC system (Acquity Ultra Performance LC; Waters Corp.) equipped with a degasser, a pump, an autosampler, and a column oven. An analytical column was a UPLC HSS T3 $(50 \mathrm{~mm} \times 2.1 \mathrm{~mm}, 1.8 \mu \mathrm{m}$ particle size; Waters Corp.). A guard column $(5 \mathrm{~mm} \times 2.1 \mathrm{~mm}, 1.8 \mu \mathrm{m}$ particle size; Waters Corp.) was used as a pre-column. The column was maintained at $40^{\circ} \mathrm{C}$. A gradient program was used with mobile phase, consisting of methanol and $0.1 \%$ formic acid with the following methanol contents: $0-2 \mathrm{~min}, 5 \% ; 2-7 \mathrm{~min}, 5-60 \%$; $7-8 \mathrm{~min}, 60-95 \%$; $8-8.5 \mathrm{~min}, 95-5 \%$; $8.5-10 \mathrm{~min}, 5 \%$. The flow rate was $0.4 \mathrm{~mL} / \mathrm{min}$. The injection volume was $2 \mu \mathrm{L}$.

The MS/MS system (Quattro Micro API; Waters Corp.) was a triple quadrupole mass spectrometer equipped with an electrospray ionization (ESI) interface. The parameters used for MS under ESI positive-ion mode were as follows: capillary voltage $1.0 \mathrm{kV}$, cone voltage $20 \mathrm{~V}$, desolvation temperature $400^{\circ} \mathrm{C}$, source temperature $120^{\circ} \mathrm{C}$, cone gas (nitrogen gas) $50 \mathrm{~L} / \mathrm{hr}$, desolvation gas (nitrogen gas) $800 \mathrm{~L} / \mathrm{hr}$, and collision gas (argon gas). Mass spectrometric detection was performed in multiple reaction monitoring (MRM) mode with the following parameters: precursor ion $m / z=192$, product ion for quantification $m / z=146$ (collision energy $=20 \mathrm{eV}$ ), and product ion for confirmation $m / z=110$ (collision energy $=30 \mathrm{eV})($ Fig. S1).

\section{Results and Discussion}

\section{Extraction and cleanup}

To establish a highly sensitive analytical method for clopyralid in cattle manure compost, we studied (1) the adequacy of extraction times and (2) the addition of a concentration process while referring to the authorized method listed in Testing Methods for Fertilizers (2017). ${ }^{7)}$
First, the validity of the repetition number of extraction times was examined using clopyralid-contaminated cattle manure compost samples. From repeating the extraction twice with methanol-1 M NaOH (99:1), a maximum 1.3-fold difference was found compared with the concentration of clopyralid detected with the reference method using single-time extraction (Table 1). Therefore, it is necessary to repeat extraction at least twice to achieve more accurate analytical values.

According to the reference method, $5 \mathrm{~mL}$ of the sample extract, corresponding to $0.25 \mathrm{~g}$ of the cattle manure compost sample, is cleaned up using Oasis HLB SPE cartridges. The final solution volume is set as $5 \mathrm{~mL}$ (matrix equivalent to $0.05 \mathrm{~g}$ of the sample/mL). Therefore, the concentration of clopyralid in the final solution is lower than that in the compost sample. As a result, this might contribute to a reduction in the matrix effect during determination with LC-MS/MS since interfering substances coexist in the final solution. However, because the LOQ is invariably low while avoiding matrix effects caused by sample

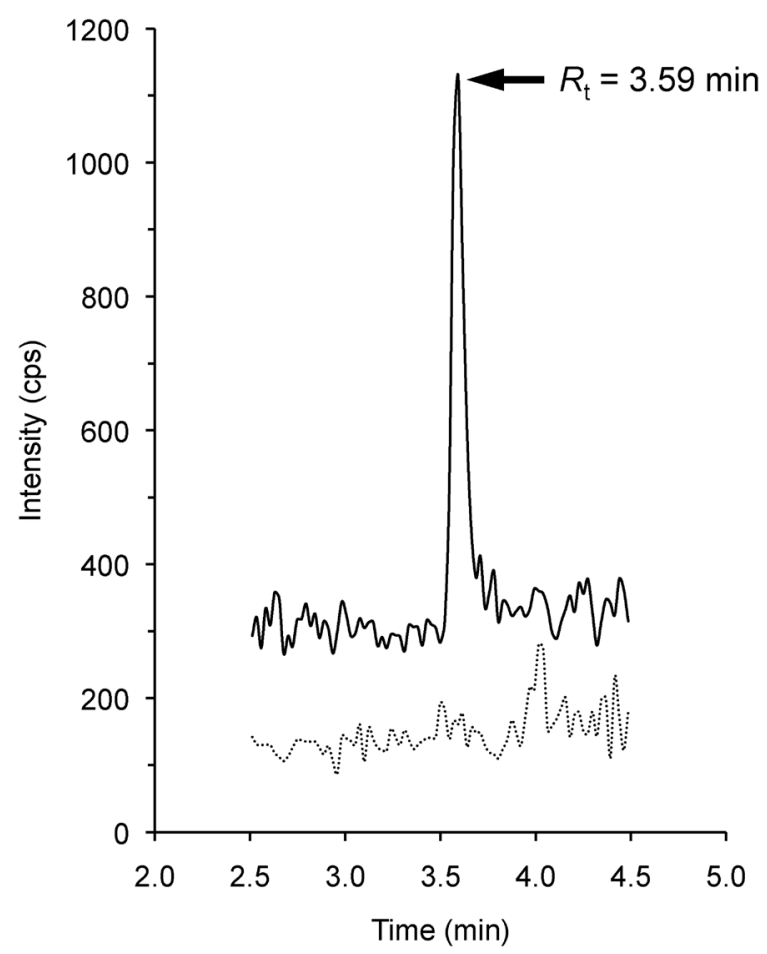

Fig. 1. UPLC-ESI (+)-MS/MS MRM chromatograms of clopyralid in cattle manure compost samples (solid line, spiked with clopyralid at $2 \mu \mathrm{g} / \mathrm{kg} \mathrm{dw}$; dotted line, blank). 
dilution, a concentration process must be applied after the cleanup procedure with SPE to lower the LOQ. Therefore, the micro liquid-liquid extraction (micro LLE) method invented by Schaner et al. ${ }^{9)}$ has been applied to the process. The concentration process was made easier by applying of the following operation using the proposed micro LLE method: (1) washing of the interfering substances coexisting in the eluate from the SPE cartridge with $1 \mathrm{MNaOH}$ and (2) quantitative re-extraction of clopyralid into the organic (dichloromethane) phase by shifting the $\mathrm{pH}$ of the aqueous phase strongly to the acidic side $(\mathrm{pH}<1.5)$ with $12 \mathrm{M} \mathrm{H}_{2} \mathrm{SO}_{4}$. The micro LLE method separates the organic phase and aqueous phase by centrifugation, unlike the classical LLE method. Therefore, this method offers the benefit that the organic phase can be easily isolated without forming an emulsion at the liquid-liquid interface. As a result, it was possible to concentrate the volume of the final solution to $0.2 \mathrm{~mL}$ by the application of micro LLE (matrix equivalent to $2.5 \mathrm{~g}$ of the sample $/ \mathrm{mL}$ ).

As portrayed in the MRM chromatograms obtained by treating the cattle manure compost samples (blank sample and spiked sample at $2 \mu \mathrm{g} / \mathrm{kg}$ dry weight (dw)) according to the proposed sample-preparation method, no interfering peak was observed near the elution time $\left(R_{t}=3.59 \mathrm{~min}\right)$ of clopyralid (Fig. 1). Furthermore, confirmation of the potential matrix effect when determining LC-MS/MS revealed that, although weak ionization suppression $(-3 \%)$ was observed in the sample extract, it was not to be regarded as a disturbance that substantially hin- ders quantitative determination. ${ }^{23)}$ In other words, results suggest that the proposed sample-preparation method is capable of removing the interfering substances suitable for LC-MS/MS. As a result, the proposed analytical method requires no internal calibration method or matrix-matched calibration method for correction of the matrix effect. Quantification using the simplest external calibration method can be done using the proposed method.

The LOQ and limit of detection (LOD) of the proposed method using the cattle manure compost samples spiked with clopyralid at $2 \mu \mathrm{g} / \mathrm{kg} \mathrm{dw}$ were estimated, respectively, ${ }^{24)}$ to be $0.7 \mu \mathrm{g} /$ $\mathrm{kg} \mathrm{dw}$ and $0.3 \mu \mathrm{g} / \mathrm{kg} \mathrm{dw}$. On the other hand, the LOQ and LOD of the reference method were $7.7 \mu \mathrm{g} / \mathrm{kg} \mathrm{dw}$ and $3.0 \mu \mathrm{g} / \mathrm{kg} \mathrm{dw}$, respectively. Because the analytical sensitivity improved approximately 10 times when comparing the LOQ with the reference method, results suggest that the proposed method has analytical sensitivity sufficient to prevent physiological crop disorders that can occur at concentrations lower than the LOQ of the reference method in cattle manure compost. Incidentally, considering that the LOQ depends on (1) the analytical performance of the LC-MS/MS owned by each laboratory, (2) the proficiency of the analytical chemist in pesticide residue analysis, (3) the amount of compost input to cropland, and (4) the concentration in soil where physiological disorder might occur, $2 \mu \mathrm{g} / \mathrm{kg} \mathrm{dw}$ is expected to be the target LOQ.

Table 2. Analytical validation (accuracy, precision, and collaborative study) of the proposed method

\begin{tabular}{|c|c|c|c|c|c|}
\hline \multicolumn{6}{|l|}{ Accuracy } \\
\hline \multicolumn{2}{|c|}{ Spiked level $(\mu \mathrm{g} / \mathrm{kg} \mathrm{dw})$} & \multicolumn{2}{|c|}{ Average recovery $(\%, n=5)$} & \multicolumn{2}{|r|}{ RSD (\%) } \\
\hline \multicolumn{2}{|r|}{2} & \multicolumn{2}{|r|}{$71.5 \pm 2.7$} & \multicolumn{2}{|r|}{3.7} \\
\hline \multicolumn{2}{|r|}{10} & \multicolumn{2}{|r|}{$78.3 \pm 2.9$} & \multicolumn{2}{|r|}{3.8} \\
\hline \multicolumn{2}{|r|}{50} & \multicolumn{2}{|r|}{$78.9 \pm 4.0$} & \multicolumn{2}{|r|}{5.0} \\
\hline \multicolumn{6}{|l|}{ Precision } \\
\hline \multicolumn{2}{|r|}{ Sample } & \multicolumn{2}{|c|}{ Within-day precision ( $\%, n=3 /$ day) } & \multicolumn{2}{|c|}{ Between-day precision $(\%, n=3 /$ day $\times 5$ days $)$} \\
\hline \multicolumn{2}{|c|}{$\begin{array}{l}\text { Cattle manure compost contaminated with low } \\
\text { concentration of clopyralid }\end{array}$} & \multicolumn{2}{|r|}{$0.4-3.0$} & \multicolumn{2}{|r|}{3.3} \\
\hline \multicolumn{2}{|c|}{$\begin{array}{l}\text { Cattle manure compost contaminated with high } \\
\text { concentration of clopyralid }\end{array}$} & \multicolumn{2}{|r|}{$0.1-2.0$} & \multicolumn{2}{|r|}{2.5} \\
\hline \multicolumn{6}{|c|}{ Collaborative study } \\
\hline \multirow[b]{2}{*}{ Sample No. } & \multicolumn{2}{|l|}{ NARO } & \multicolumn{2}{|l|}{ FAMIC } & \multirow{2}{*}{$\begin{array}{l}\text { Ratio of concentration } \\
\text { (FAMIC/NARO) }\end{array}$} \\
\hline & $\begin{array}{l}\text { Detected concentration } \\
\quad(\mu \mathrm{g} / \mathrm{kg} \mathrm{dw}, n=5)\end{array}$ & RSD (\%) & $\begin{array}{l}\text { Detected concentration } \\
\quad(\mu \mathrm{g} / \mathrm{kg} \mathrm{dw}, n=5)\end{array}$ & $\mathrm{RSD}(\%)$ & \\
\hline 1 & $4.5 \pm 0.2$ & 4.1 & $5.0 \pm 0.4$ & 7.2 & 1.1 \\
\hline 2 & $15.6 \pm 0.1$ & 0.9 & $14.5 \pm 1.4$ & 9.6 & 0.93 \\
\hline 3 & $42.1 \pm 1.6$ & 3.8 & $40.0 \pm 2.3$ & 5.8 & 0.95 \\
\hline 4 & $49.7 \pm 0.8$ & 1.7 & $49.5 \pm 1.3$ & 2.6 & 1.0 \\
\hline 5 & $100.7 \pm 3.7$ & 3.7 & $96.4 \pm 7.0$ & 7.3 & 0.96 \\
\hline 6 & $186.8 \pm 5.0$ & 2.7 & $170.0 \pm 13.2$ & 7.7 & 0.91 \\
\hline
\end{tabular}


Table 3. Comparison of analytical results between the proposed and the reference methods with commercially available clopyralid-contaminated cattle manure compost samples

\begin{tabular}{|c|c|c|c|c|}
\hline \multirow{2}{*}{ Sample No. } & \multicolumn{2}{|l|}{ Proposed method } & \multicolumn{2}{|l|}{ Reference method } \\
\hline & Detected concentration $(\mu \mathrm{g} / \mathrm{kg} \mathrm{dw}, n=5)$ & RSD (\%) & Detected concentration $(\mu \mathrm{g} / \mathrm{kg} \mathrm{dw}, n=5)$ & $\operatorname{RSD}(\%)$ \\
\hline 1 & $0.94 \pm 0.1$ & 5.6 & Not analyzed & - \\
\hline 2 & $3.3 \pm 0.3$ & 8.1 & Not analyzed & - \\
\hline 3 & $81.0 \pm 1.7$ & 2.0 & $68.8 \pm 3.9$ & 5.7 \\
\hline 4 & $93.0 \pm 4.2$ & 4.5 & $88.1 \pm 1.8$ & 2.0 \\
\hline 5 & $106.1 \pm 5.4$ & 5.1 & $89.4 \pm 2.5$ & 2.8 \\
\hline 6 & $114.9 \pm 5.7$ & 5.0 & $99.8 \pm 7.4$ & 7.4 \\
\hline 7 & $115.1 \pm 6.6$ & 5.7 & $115.8 \pm 3.5$ & 3.0 \\
\hline 8 & $121.5 \pm 9.7$ & 8.0 & $119.9 \pm 4.5$ & 3.7 \\
\hline 9 & $143.3 \pm 6.9$ & 4.8 & $131.3 \pm 5.5$ & 4.2 \\
\hline
\end{tabular}

2. Analytical validation (accuracy, precision and collaborative study)

The accuracy of the proposed method was confirmed using the cattle manure compost samples spiked with clopyralid at 2, 10, and $50 \mu \mathrm{g} / \mathrm{kg} \mathrm{dw}$. As shown in Table 2, the average recovery was $71-79 \%$. The relative standard deviation (RSD) was $5 \%$ or less. Confirmation of the precision of the proposed method (within-day precision, $n=3 /$ day; between-day precision, $n=3$ /day $\times 5$ days) using cattle manure compost samples contaminated with low and high concentrations revealed that both variations were $3.3 \%$ or less (Table 2 ).

To confirm reproducibility among laboratories, the National Agriculture and Food Research Organization (NARO) and the Food and Agricultural Materials Inspection Center (FAMIC) shared clopyralid-contaminated cattle manure compost samples of six kinds. Then a collaborative study was conducted. In the FAMIC, the quantification of clopyralid was carried out according to analytical conditions previously reported. ${ }^{14)}$ Table 2 shows that the ratio of the average detected concentrations of clopyralid obtained at two laboratories was $0.91-1.11$. No statistically significant difference was found between their analytical values (Student $t$ test, $p=0.196$ ). These results suggest that the proposed method has sufficient accuracy and precision for the analysis of clopyralid residue in cattle manure compost samples.

\section{Application of the proposed method to clopyralid-contaminat- ed cattle manure compost samples}

The proposed method and the reference method were applied to nine commercially available clopyralid-contaminated cattle manure compost samples. Comparison of both analytical values (Table 3) revealed that, although almost equal values were obtained for the two samples, differences of 1.1-1.2 times were found in the values of the five samples. Because the micro LLE is given to the proposed method, the probability of clopyralid loss during the sample-preparation procedures is regarded as higher than that in the reference method. However, contrary to this hypothesis, higher analytical values than those for the reference method are probably achieved because of the different num- bers of extraction repetitions described above. Furthermore, the results demonstrate that clopyralid can be detected even from cattle manure compost samples contaminated at very low concentrations, for which detection is difficult using the reference method.

In conclusion, we improved extraction methods and used a concentration process with micro LLE based on the reference method. Thereby, we established a highly sensitive analytical method able to detect clopyralid residues in cattle manure compost samples contaminated at extremely low concentrations without matrix effects. The analytical method for clopyralid residues in cattle manure compost samples established in this study fulfills analytical requirements such as accuracy and precision for utilization as a practical routine analytical method. Therefore, its application to clopyralid residue monitoring surveys of cattle manure compost samples is anticipated.

\section{Acknowledgements}

This work was supported by a grant from the Ministry of Agriculture, Forestry, and Fisheries of Japan (28045C). We appreciate Dr. Yuji Shirai (Fertilizer and Feed Inspection Department, FAMIC), who cooperated in the collaborative study, and Dr. Koji Ito (Institute for Agro-Environmental Sciences, NARO) for giving excellent technical assistance. The authors thank Fastek, Ltd. (Miyagi, Japan, http://www.fastekjapan.com/) for English-language review of this report.

\section{References}

1) J. A. Turner (eds.): “The Pesticide Manual”, 17th Ed., British Crop Protection Council, Hampshire, UK, 2015.

2) http://www.maff.go.jp/j/seisan/kankyo/clopyralid/attach/pdf/clopy ralid-31.pdf (Accessed 19 Nov., 2018) (in Japanese).

3) S. Namiki, N. Seike and E. Watanabe: J. Pestic. Sci., accepted.

4) http://www.naro.affrc.go.jp/publicity_report/publication/files/clopy ralid_disorder.pdf (Accessed 19 Nov., 2018) (in Japanese).

5) http://www.maff.go.jp/j/seisan/kankyo/clopyralid/attach/pdf/clopy ralid-25.pdf (Accessed 19 Nov., 2018) (in Japanese).

6) http://www.maff.go.jp/j/seisan/kankyo/clopyralid/attach/pdf/clopy ralid-33.pdf (Accessed 19 Nov., 2018) (in Japanese).

7) http://www.famic.go.jp/ffis/fert/obj/shikenho_2017_10.pdf\#page =1 
(Accessed November 19, 2018) (in Japanese).

8) C. Díez, W. A. Traag, P. Zommer, P. Marinero and J. Atienza: J. Chromatogr. A 1131, 11-23 (2006).

9) A. Schaner, J. Konecny, L. Luckey and H. Hickes: J. AOAC Int. 90, 1402-1410 (2007).

10) U. Koesukwiwat, K. Sanguankaew and N. Leepipatpiboon: Anal. Chim. Acta 626, 10-20 (2008).

11) R. Saito, O. Ikenaga, S. Ishihara, H. Shibata, T. Iwafune, T. Sato and Y. Yamashita: J. Pestic. Sci. 35, 479-482 (2010).

12) O. Lacina, M. Zachariasova, J. Urbanova, M. Vaclavikova, T. Cajka and J. Hajslova: J. Chromatogr. A 1262, 8-18 (2012).

13) P. Zhang, A. Bui, G. Rose and G. Allinson: J. Chromatogr. A 1325, 56-64 (2014).

14) http://www.famic.go.jp/ffis/fert/obj/kenkyu/kenkyu14.pdf (in Japanese).

15) P. Kaczyński, B. Łozowicka, M. Jankowska and I. Hrynko: Talanta 152, 127-136 (2016).
16) S. Butz, Th. Heberer and H.-J. Stan: J. Chromatogr. A 677, 63-74 (1994).

17) L. K. Tan, D. Humphries, P. Y. P. Yeung and L. Z. Florence: J. Agric. Food Chem. 44, 1135-1143 (1996).

18) S. Schütz, H. Vedder, R.-A. Düring, B. Weissbecker and H. E. Hummel: J. Chromatogr. A 754, 265-271 (1996).

19) C. Raeppel, M. Nief, M. Fabritius, L. Racault, B. M. Appenzeller and M. Millet: J. Chromatogr. A 1218, 8123-8129 (2011).

20) A. Hercegová, M. Dömötörová and E. Matisová: J. Chromatogr. A 1153, 54-73 (2007).

21) M. LeDoux: J. Chromatogr. A 1218, 1021-1036 (2011).

22) S. Grimalt and P. Dehouck: J. Chromatogr. A 1433, 1-23 (2016).

23) P. A. S. Tette, L. R. Guidi, M. B. A. Glória and C. Fernandes: Talanta 149, 124-141 (2016).

24) https://www.env.go.jp/chemi/anzen/chosa/tebiki-h20.pdf (Accessed 19 Nov., 2018) (in Japanese). 